\title{
Crystal structures of IspF from Plasmodium falciparum and Burkholderia cenocepacia: comparisons inform antimicrobial drug target assessment
}

Patrick EF O'Rourke1, Justyna Kalinowska-Tłuścik², Paul K Fyfe ${ }^{1}$, Alice Dawson ${ }^{1}$ and William N Hunter ${ }^{1 *}$

\begin{abstract}
Background: 2C-methyl-D-erythritol-2,4-cyclodiphosphate synthase (IspF) catalyzes the conversion of 4-diphosphocytidyl-2C-methyl-D-erythritol-2-phosphate to 2C-methyl-D-erythritol-2,4-cyclodiphosphate and cytidine monophosphate in production of isoprenoid-precursors via the methylerythritol phosphate biosynthetic pathway. IspF is found in the protozoan Plasmodium falciparum, a parasite that causes cerebral malaria, as well as in many Gram-negative bacteria such as Burkholderia cenocepacia. IspF represents a potential target for development of broad-spectrum antimicrobial drugs since it is proven or inferred as essential in these pathogens and absent from mammals. Structural studies of IspF from these two important yet distinct pathogens, and comparisons with orthologues have been carried out to generate reagents, to support and inform a structure-based approach to early stage drug discovery.
\end{abstract}

Results: Efficient recombinant protein production and crystallization protocols were developed, and high-resolution crystal structures of IspF from P. falciparum (PflspF) and B. cenocepacia (BclspF) in complex with cytidine nucleotides determined. Comparisons with orthologues, indicate a high degree of order and conservation in parts of the active site where $\mathrm{Zn}^{2+}$ is bound and where recognition of the cytidine moiety of substrate occurs. However, conformational flexibility is noted in that area of the active site responsible for binding the methylerythritol component of substrate. Unexpectedly, one structure of $B \mathrm{ClspF}$ revealed two molecules of cytidine monophosphate in the active site, and another identified citrate coordinating to the catalytic $\mathrm{Zn}^{2+}$. In both cases interactions with ligands appear to help order a flexible loop at one side of the active site. Difficulties were encountered when attempting to derive complex structures with other ligands.

Conclusions: High-resolution crystal structures of IspF from two important human pathogens have been obtained and compared to orthologues. The studies reveal new data on ligand binding, with citrate coordinating to the active site $\mathrm{Zn}^{2+}$ and when present in high concentrations cytidine monophosphate displays two binding modes in the active site. Ligand binding appears to order a part of the active site involved in substrate recognition. The high degree of structural conservation in and around the IspF active site suggests that any structural model might be suitable to support a program of structure-based drug discovery.

Keywords: Antimicrobial drug target, Isoprenoid biosynthesis, X-ray crystallography, Zn $\mathrm{n}^{2+}$-dependent enzyme

\footnotetext{
* Correspondence: w.n.hunter@dundee.ac.uk

'Division of Biological Chemistry and Drug Discovery, College of Life

Sciences, University of Dundee, Dundee, DD1 5EH, UK

Full list of author information is available at the end of the article
} 


\section{Background}

Isoprenoids contribute to a myriad of essential biological functions, for example as the prenyl groups that anchor proteins to membranes, as components of respiratory membranes, enzyme cofactors, and as scaffolds for the assembly of glycan structures [1-4]. Two distinct biosynthetic routes supply the universal isoprenoid-precursors isopentenyl pyrophosphate and dimethylallyl pyrophosphate. The mevalonate (MVA) pathway is present in animals, fungi and archaea while the $2 C$-methyl-D-erythritol-4-phosphate (MEP) pathway is widely distributed in bacteria, algae and several apicomplexan parasites, including Plasmodium species responsible for malaria [5,6]. Both MVA and MEP pathways occur in plants; the former operates in the cytoplasm and the latter in chloroplasts [7]. In most apicomplexan parasites the components of the MEP pathway are localized to an organelle known as the apicoplast, a relict chloroplast, which is also responsible for additional biosynthetic processes [8]. The organelle, which resembles a cyanobacterium is thought to have been acquired from an ancestral endosymbiotic event with an alga. All MEP pathway enzymes in P. falciparum are synthesized in the cytoplasm but they carry an apicoplast targeting sequence, which then drives localization [8]. The disruption of apicoplast replication results in parasites that are isopentenyl pyrophosphate auxotrophs [9].

Part of the interest in the MEP pathway concerns antimicrobial drug research and several observations support the idea that the pathway contains potential drug targets, enzymes whose inhibition may provide broad- spectrum antimicrobial activity [5,6]. We identified the $\mathrm{Zn}^{2+}$-dependent 2C-methyl-D-erythritol-2,4-cyclodiphosphate synthase [EC: 4.6.1.12] the fifth enzyme in the pathway as a target of interest. This enzyme, also known as IspF, catalyzes the conversion of 4-diphosphocytidyl-2C-methylD-erythritol-2-phosphate (CDP-MEP) to $2 C$-methyl-Derythritol-2,4-cyclodiphosphate (MEcPP) and cytidine monophosphate (CMP, Figure 1). We considered a diverse set of criteria that have been established as key with respect to target assessment for early stage antimicrobial drug discovery [10]. These criteria include genetic and chemical validation of the target, and the availability of accurate structural information and appropriate reagents to guide the development of structureactivity relationships. Three primary factors were taken into consideration. First, genetic methods have identified that individual components of the pathway, including IspF are essential for bacterial survival. For example, the essentiality of the $i s p F$ gene for growth and survival of Bacillus subtilis, Escherichia coli and Mycobacterium tuberculosis is established [11-15]. Secondly, this pathway is absent from humans $[5,6]$ potentially mitigating against toxicity issues. Thirdly, chemical validation of the pathway is provided by the antibacterial fosmidomycin, a potent inhibitor of 1-deoxy-D-xylulose 5-phosphate reductoisomerase, an enzyme that contributes to an early stage in the pathway. This last point regarding validation is reinforced by further work, which shows that fosmidomycin and derivatives are also efficacious in killing P. falciparum [16-18].

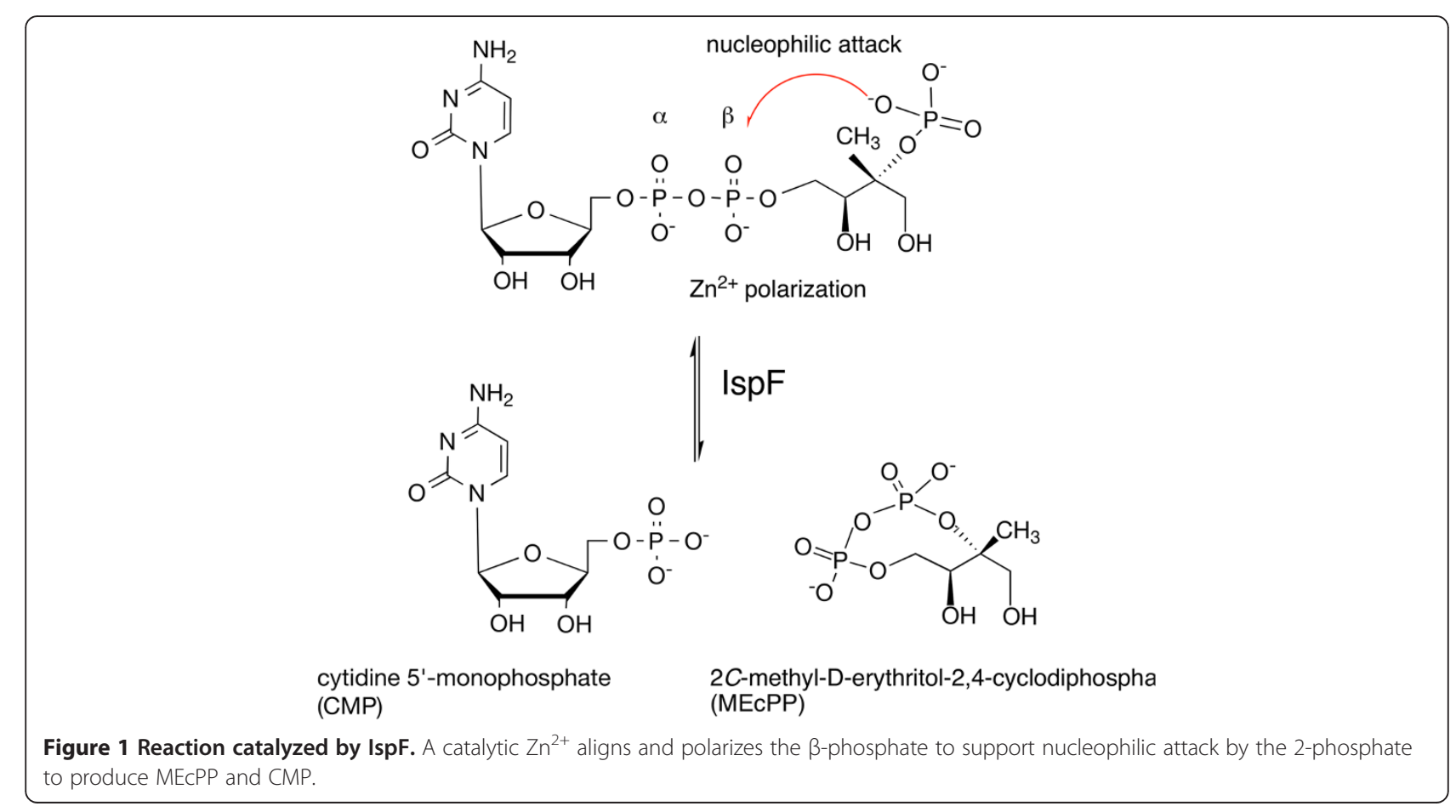


Previous studies have provided insight into aspects of IspF structure, specificity, and mechanism [19-22]. The structure of IspF has been derived from a dozen species in addition to the two new ones disclosed in this publication. More recently new IspF ligands including potent inhibitors have been identified [23-25], some of which have also been shown to inhibit the growth of $P$. falciparum within infected erythrocytes with respectable $I C_{50}$ values of 1.4$1.6 \mu \mathrm{M}$ [26]. These approaches have been complemented by NMR-based fragment screening and co-crystallization efforts targeting IspF from B. pseudomallei (BpIspF) [27].

\section{Aims}

We sought to further inform the assessment of IspF as a drug target with crystallographic studies of the enzyme from two serious human pathogens, the Gram-negative bacterium Burkholderia cenocepacia (BcIspF) and the parasitic protozoan Plasmodium falciparum (Pf IspF).

\section{Results and discussion The structure of IspF}

Efficient recombinant protein production systems, purification protocols and reproducible crystallization conditions have been established for $B c I s p F$ and $P f$ IspF leading to yields of up to $25 \mathrm{mg} \mathrm{L}^{-1}$ and $2.5 \mathrm{mg} \mathrm{L}^{-1}$ of $E$. coli culture respectively. High-resolution crystal structures of $B c I s p F$ in complex with CMP or citrate, and of $P f I s p F$ in complex with CDP, as well as an unliganded $P f$ IspF structure have been determined. Crystallographic statistics are presented in Tables 1 and 2.

The calculated masses of the BcIspF and PfIspF subunits are $19.3 \mathrm{kDa}$ and $20.5 \mathrm{kDa}$ respectively and the polypeptide folds into a single $\alpha / \beta$ domain that consists of a four-stranded mixed $\beta$-sheet on one side with three $\alpha$-helices on the other (Figure 2). IspF forms a stable homotrimer as observed in size-exclusion chromatography, which returns an estimate of $60 \mathrm{kDa}$ for each. In all IspF crystal structures three subunits form a compact bell-shaped assembly approximately $45 \AA$ by $60 \AA$ in the axial and equatorial dimensions respectively (Figure 2 ). A surface area approximately equivalent to that of one subunit is buried on oligomerization. The accessible surface area (ASA) of an IspF monomer averages out as approximately $8130 \AA^{2}$ for $B c$ IspF and $8680 \AA^{2}$ for Pf IspF. The ASA for the $B c$ IspF trimer is $16080 \AA^{2}$, and for the Pf IspF trimer $18180 \AA^{2}$. In the case of $B c$ IspF the asymmetric unit consists of three subunits, chains A, B, C, which are related by three-fold non-crystallographic symmetry (NCS). NCS is high with least squares overlays of $161 C \alpha$ positions in the range $0.2-0.3 \AA$. One subunit is present in the asymmetric unit of $P f I s p F$ and the trimer is generated by the symmetry operations $(-\mathrm{x}+\mathrm{y},-\mathrm{x}, \mathrm{z})$ and $(-\mathrm{y}, \mathrm{x}-\mathrm{y}, \mathrm{z})$. A least squares superimposition of $\mathrm{C} \alpha$ positions from both $\mathrm{Pf}$ IspF
Table 1 Crystallographic statistics for Pf IspF

\begin{tabular}{|c|c|c|}
\hline Structure/PDB & Pf IspF:CDP/4C81 & $\begin{array}{l}\text { Unliganded } \\
\text { Pf IspF/4C82 }\end{array}$ \\
\hline Space group & $H 3$ & $H 3$ \\
\hline \multicolumn{3}{|l|}{ Unit cell dimensions } \\
\hline$a, b, c(\AA)$ & $84.9,84.9,101.0$ & $84.2,84.2,102.5$ \\
\hline Resolution range ${ }^{\mathbf{a}}(\AA)$ & $41.63-1.60(1.69-1.60)$ & $29.71-2.00(2.11-2.00)$ \\
\hline No. reflections & 181781 (16968) & $41802(5780)$ \\
\hline Unique reflections & 35607 (5194) & $18068(2622)$ \\
\hline Completeness (\%) & 99.4 (99.3) & $98.6(97.0)$ \\
\hline$R_{\text {merge }} \mathbf{b}(\%)$ & $9.3(42.0)$ & $9.4(48.2)$ \\
\hline Multiplicity & $5.1(3.3)$ & $2.3(2.2)$ \\
\hline$<\mid / \sigma(\mid)>$ & $11.1(2.6)$ & $5.3(2.0)$ \\
\hline Wilson $B\left(\AA^{2}\right)$ & 24.4 & 32.0 \\
\hline$R_{\text {work }}{ }^{\mathrm{c}} / R_{\text {free }}{ }^{\mathbf{d}}(\%)$ & $14.4,16.5$ & $19.4,22.6$ \\
\hline $\begin{array}{l}\text { Number of residues/ } \\
\text { waters/ligands }\end{array}$ & $\begin{array}{l}156,85 \text { waters, } 1 \mathrm{CDP} \\
2 \mathrm{Zn}^{2+}, 3 \mathrm{Cl}^{-}, 1 \mathrm{SO}_{4}^{2-}\end{array}$ & $\begin{array}{l}156,94 \text { waters, } \\
2 \mathrm{Zn}^{2+}, 1 \mathrm{SO}_{4}^{2-}\end{array}$ \\
\hline $\begin{array}{l}\text { RMSD bond } \\
\text { lengths }(\AA) /\end{array}$ & 0.005 & 0.019 \\
\hline Bond angles $\left({ }^{\circ}\right)$ & 1.000 & 2.087 \\
\hline \multicolumn{3}{|l|}{ Mean $B$-factors $\left(\AA^{2}\right)$} \\
\hline Overall & 22.9 & 37.6 \\
\hline Main chain, side chain & $25.1,33.8$ & $34.2,39.5$ \\
\hline Waters & 35.2 & 47.8 \\
\hline \multirow[t]{2}{*}{ Ligands } & $34.9,28.3(0.6,0.4 \mathrm{CDP})$ & $44.5\left(\mathrm{Zn}^{2+}, \mathrm{SO}_{4}^{2-}\right)$ \\
\hline & $35.8\left(\mathrm{Zn}^{2+}, \mathrm{Cl}^{-}, \mathrm{SO}_{4}^{2-}\right)$ & \\
\hline \multicolumn{3}{|l|}{ Ramachandran plot } \\
\hline Favoured regions (\%) & 98.6 & 95.3 \\
\hline Allowed regions (\%) & 0.7 & 4.0 \\
\hline Outliers & 1 outlier: Asp79 & 1 outlier: Asp79 \\
\hline
\end{tabular}

${ }^{\mathrm{a}}$ Values in parentheses refer to the highest resolution shell. ${ }^{\mathrm{b}} R_{\text {merge }}=\Sigma_{h k l} \Sigma_{i} \|_{i}$ $(h k l)-\langle l(h k l)\rangle \mid / \sum_{h k l} \sum i_{i}(h k l)$; where $l_{i}(h k l)$ is the intensity of the ith measurement of reflection $h k l$ and $\left\langle l(h k l)>\right.$ is the mean value of $l_{i}(h k l)$ for all $i$ measurements. ${ }^{c} R_{\text {work }}=\sum_{h k} \|\left|F_{o}\right|-\left|F_{c}\right| / \Sigma\left|F_{o}\right|$, where $F_{o}$ is the observed structure factor and $F_{c}$ is the calculated structure factor. ${ }^{\mathrm{d}} R_{\text {free }}$ is the same as $R_{\text {work }}$ except calculated with a subset, $5 \%$, of data that are excluded from the refinement calculations.

structures matches all 156 residues with an RMSD of $0.3 \AA$. Since there are no pronounced differences between the CDP bound and unliganded $P f \mathrm{IspF}$ structures only the former is discussed.

Structural comparisons of IspF orthologues from the Protein Data Bank (PDB) were carried out using the $D A L I$ server [28]. Pairwise sequence identities range from 28 to $90 \%$, Z scores from 18 to 31 and RMSD values from 0.3 to $2.5 \AA$. The apicoplast targeting sequence of Plasmodium spp. and the chloroplast targeting sequence of Arabidopsis thaliana IspF were excluded in the calculation of sequence identities. Using representative IspF structures from each of the twelve unique organisms in the PDB, an average RMSD of $\mathrm{C} \alpha$ positions was 
Table 2 Crystallographic statistics for BclspF

\begin{tabular}{|c|c|c|c|}
\hline Structure/PDB & BclspF:CMP/4C8G & BclspF:2CMP/4C8E & BclspF:citrate/4C8I \\
\hline Space group & $C 2$ & $C 2$ & $C 2$ \\
\hline \multicolumn{4}{|l|}{ Unit cell dimensions } \\
\hline$a, b, c(\AA)$ & $97.2,88.6,72.4$ & $97.9,89.3,73.0$ & 131.7, 52.5, 72.1, \\
\hline$\beta$ & $103.9^{\circ}$ & $104.2^{\circ}$ & $94.6^{\circ}$ \\
\hline Resolution range $(\AA)$ & $29.84-2.00(2.10-2.00)$ & $19.32-1.90(2.00-1.90)$ & $40.90-2.00(2.10-2.00)$ \\
\hline No. reflections & 98451 (13335) & $164120(24760)$ & 119715 (15957) \\
\hline Unique reflections & 38409 (5579) & 47918 (6972) & $33460(4696)$ \\
\hline Completeness (\%) & $96.0(95.4)$ & $99.9(100.0)$ & $99.4(96.1)$ \\
\hline$R_{\text {merge }}(\%)$ & $11.0(32.2)$ & $13.8(32.3)$ & $3.2(7.8)$ \\
\hline Multiplicity & $2.6(2.4)$ & $3.4(3.6)$ & $3.6(3.4)$ \\
\hline$<\mid / \sigma(\mid)>$ & $5.9(2.7)$ & $6.2(3.1)$ & $23.9(12.8)$ \\
\hline Wilson $B\left(\AA^{2}\right)$ & 16.5 & 16.3 & 18.7 \\
\hline$R_{\text {work }} / R_{\text {free }}(\%)$ & $23.7,28.0$ & $20.4,25.1$ & $15.6,19.8$ \\
\hline Number of residues & 458,173 waters, & 483,420 waters, & 460, 320 waters, \\
\hline \multirow[t]{2}{*}{ Waters/ligands } & $3 \mathrm{CMP}, 3 \mathrm{Zn}^{2+}, 1 \mathrm{Mg}^{2+}, 1 \mathrm{PO}_{4}^{3-}$ & $6 \mathrm{CMP}, 3 \mathrm{Zn}^{2+}, 1 \mathrm{SO}_{4}^{2-}$ & 3 citrates, $3 \mathrm{Zn}^{2+}, 1 \mathrm{PO}_{4}^{3-}$ \\
\hline & & 1di(hydroxyethyl)ether & \\
\hline RMSD bond lengths $(\AA) /$ & 0.020 & 0.011 & 0.020 \\
\hline bond angles $\left({ }^{\circ}\right)$ & 2.198 & 1.526 & 2.101 \\
\hline \multicolumn{4}{|l|}{ Mean $B$-factors $\left(\AA^{2}\right)$} \\
\hline Overall & 14.5 & 17.2 & 18.9 \\
\hline Main chain, side chain & $13.6,15.3$ & $18.7,20.4$ & $16.2,20.1$ \\
\hline Waters & 16.5 & 29.9 & 26.7 \\
\hline \multirow[t]{3}{*}{ Ligands } & $15.1(\mathrm{CMP}) 24.8\left(\mathrm{Zn}^{2+}, \mathrm{Mg}^{2+}, \mathrm{PO}_{4}^{3-}\right)$ & $18.2(\mathrm{CMP} 1)$ & 23.4, 36.8, 43.1 (citrates) \\
\hline & & 28.7 (CMP 2) & $26.1\left(\mathrm{Zn}^{2+}, \mathrm{PO}_{4}^{3-}\right)$ \\
\hline & & 25.0 (other ligands) & \\
\hline \multicolumn{4}{|l|}{ Ramachandran plot } \\
\hline Favoured regions (\%) & 96.9 & 97.8 & 97.7 \\
\hline Allowed regions (\%) & 2.2 & 2.2 & 2.3 \\
\hline Outliers & 4 outliers: Ser37A/C, Tyr29B, Gly17C & & \\
\hline
\end{tabular}

calculated against both proteins. The mean of the average RMSD was $1.5 \AA$ and therefore the comparisons are indicative of an enzyme that has a highly conserved structure.

The two IspF variants studied here, with sequence identity of $38 \%$, a DALI Z score 23 and RMSD value typically around $1.7 \AA$, can be taken to represent a comparison of structures that are amongst the most divergent. A structure-based sequence alignment of $B c \mathrm{IspF}$ with $P f$ IspF is shown in Figure 3 and this, together with comparisons based on consideration of 854 IspF sequences, provides a context in which to discuss key features. Pf IspF contains a 19 residue insertion at the N-terminus, Lys76 - Glu94, immediately after $\beta 1$ that does not align with bacterial IspF sequences. Here, residues Tyr82 - Phe97 could not be modeled due to the lack of ordered electron density (Figure 2c).
The most similar structures of each new IspF structure were noted. $B c$ IspF aligns 151 residues with an RMSD of $0.4 \AA$ to $B p \operatorname{IspF}(Z=31,90 \%$ sequence identity). Pf IspF aligns $143 \mathrm{C} \alpha$ positions with an RMSD of $0.8 \AA$, and 151 residues with an RMSD of $1.2 \AA$ with subunits of the enzyme from $P$. vivax ( $P v \mathrm{IspF}, \mathrm{Z}=25,66 \%$ sequence identity) and $A$. thaliana (AtIspF, $\mathrm{Z}=25,42 \%$ sequence identity) respectively. The $P v \mathrm{IspF}$ structure at $2.3 \AA$ resolution was deposited in the PDB without an associated publication [PDB: $3 \mathrm{~B} 6 \mathrm{~N}$ ]. Although $\mathrm{Zn}^{2+}$ has been modeled at the active site (discussed below), the corresponding $B$-factor of $119 \AA^{2}$ is 2.6 times greater than the average $B$-factor of the protein atoms, $46 \AA^{2}$, and the side chain of a coordinating histidine, His170, is poorly oriented. We conclude that a water molecule may be a more likely occupant of this metal binding site. In 

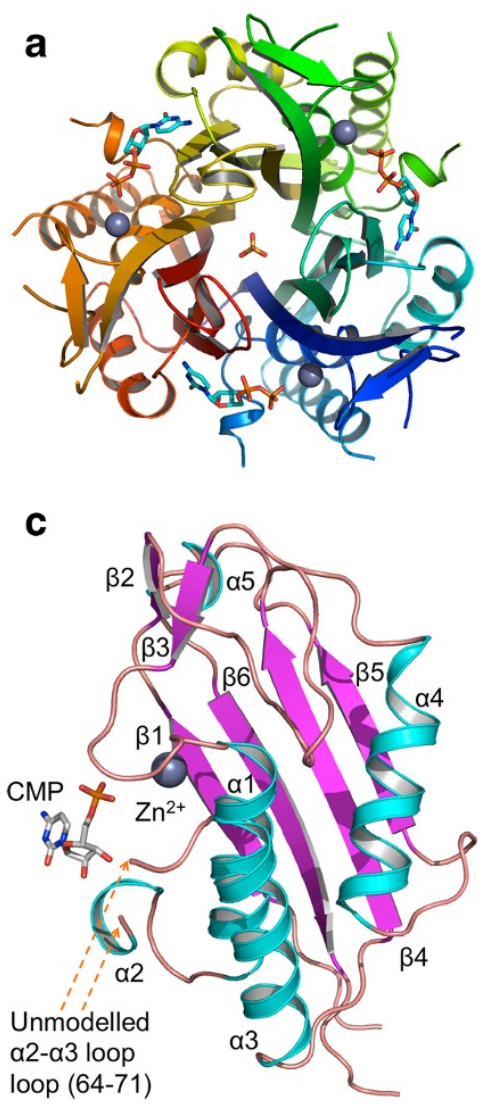
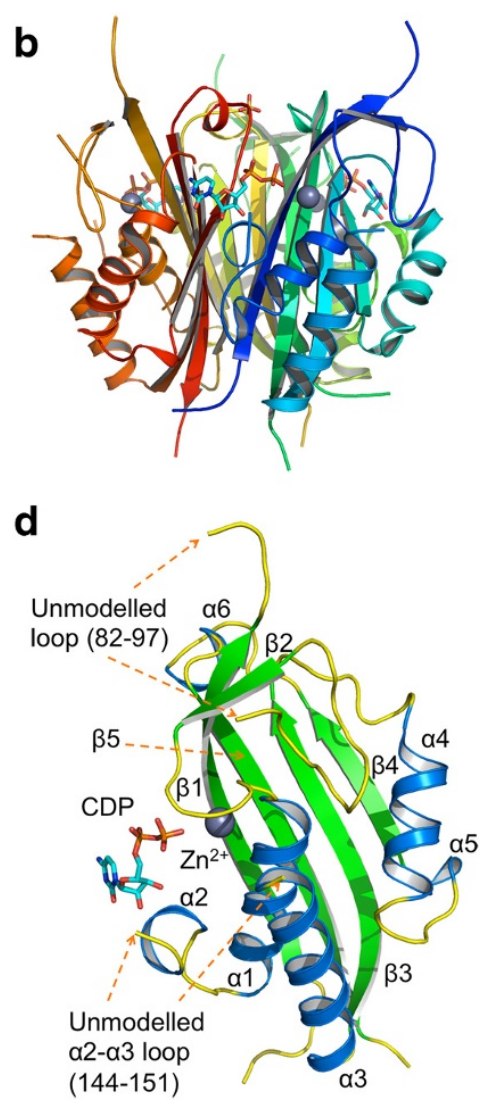

Figure 2 Overall structure of IspF. IspF forms a homotrimer. a) Axial view. b) Side view. The figure has been drawn using the coordinates for PfIspF in complex with CDP; a trimer has been generated from symmetry-related subunits. Subunits (displayed as ribbons) are colored blue, orange and green respectively. $\mathrm{Zn}^{2+}$ cations are displayed as grey spheres, sulfate and CDP are displayed as sticks. The secondary structure of PfIspF and BclspF subunits is shown in $\mathbf{c}$ ) and $\mathbf{d}$ ) respectively, similarly orientated. The location of missing loops is highlighted with arrows.

contrast, in our structure of a Plasmodium IspF, which is at $1.60 \AA$ resolution, the $B$-value for $\mathrm{Zn}^{2+}$ of $20 \AA^{2}$ is lower than the average $B$-factor over all the protein atoms of $29 \AA^{2}$.

The enzyme active site is located in a cleft at the interface of two subunits (Figure 2a) and here $\mathrm{Zn}^{2+}$ is coordinated by the side chains of two histidines and an aspartate [19]. The coordinating residues are Asp10, His 12 and His44 in BcIspF, Asp71, His73 and His123 in $P f$ IspF (Figures 3 and 4). These residues are strictly conserved in IspF. In the $E$. coli enzyme (EcIspF) Glu135, helps coordinate either a $\mathrm{Mg}^{2+}$ or $\mathrm{Mn}^{2+}$ together with the bridging phosphates of the substrate or CDP $[19,20]$. Although the residue is conserved as Glu137/216 (Figure 4 ) we do not observe any cation binding here. In $81 \%$ of IspF sequences a glutamate is observed at this position, and this is conservatively replaced by aspartate in a further $18 \%$.

The highly conserved histidine and serine combination (Pf IspF: His115-Ser116, BcIspF: His36-Ser37, identical in over $96 \%$ IspF sequences) located on the loop that leads to $\alpha 1$, adjacent to the $\mathrm{Zn}^{2+}$ binding site (Figure $2 \mathrm{c}, \mathrm{d}$ ), display elevated $B$-factors in all structures and in one chain of the BcIspF:CMP complex the electron density was of insufficient quality to allow the region to be modelled, indicating a degree of flexibility. Electron density is absent or poorly defined for the loop linking $\alpha 2$ to $\alpha 3$ in many of the IspF structures. This segment occurs at one side of the active site (Asp144 - Asn151 in Pf IspF) and (Phe63 - Ala73 in BcIspF). This $\alpha 2$ - $\alpha 3$ loop could be modeled in the $B c$ IspF:2CMP complex although the residues have elevated $B$-factors (average $47 \AA^{2}$ ), compared to the average $B$-value for the entire protein $\left(19 \AA^{2}\right)$. The same loop was also modelled for chain $A$ in the $B c$ IspF-citrate complex. These observations are consistent with the inference that the $\alpha 2$ - $\alpha 3$ loop on one side of the active site is flexible $[16,17]$.

A hydrophobic cavity occurs at the core of the IspF trimer. In $B c$ IspF the cavity is lined by the side chains of Tyr9, Val11, Ile101 and Tyr141, and the floor of the cavity is formed by a ring of six hydrophobic residues, Val3 and Leu155 donated by all three subunits. Similarly in Pf IspF side chains of Tyr70, Ile72, Ile180 and Val220 line this cavity, and the side chains of Phe 230 form the 


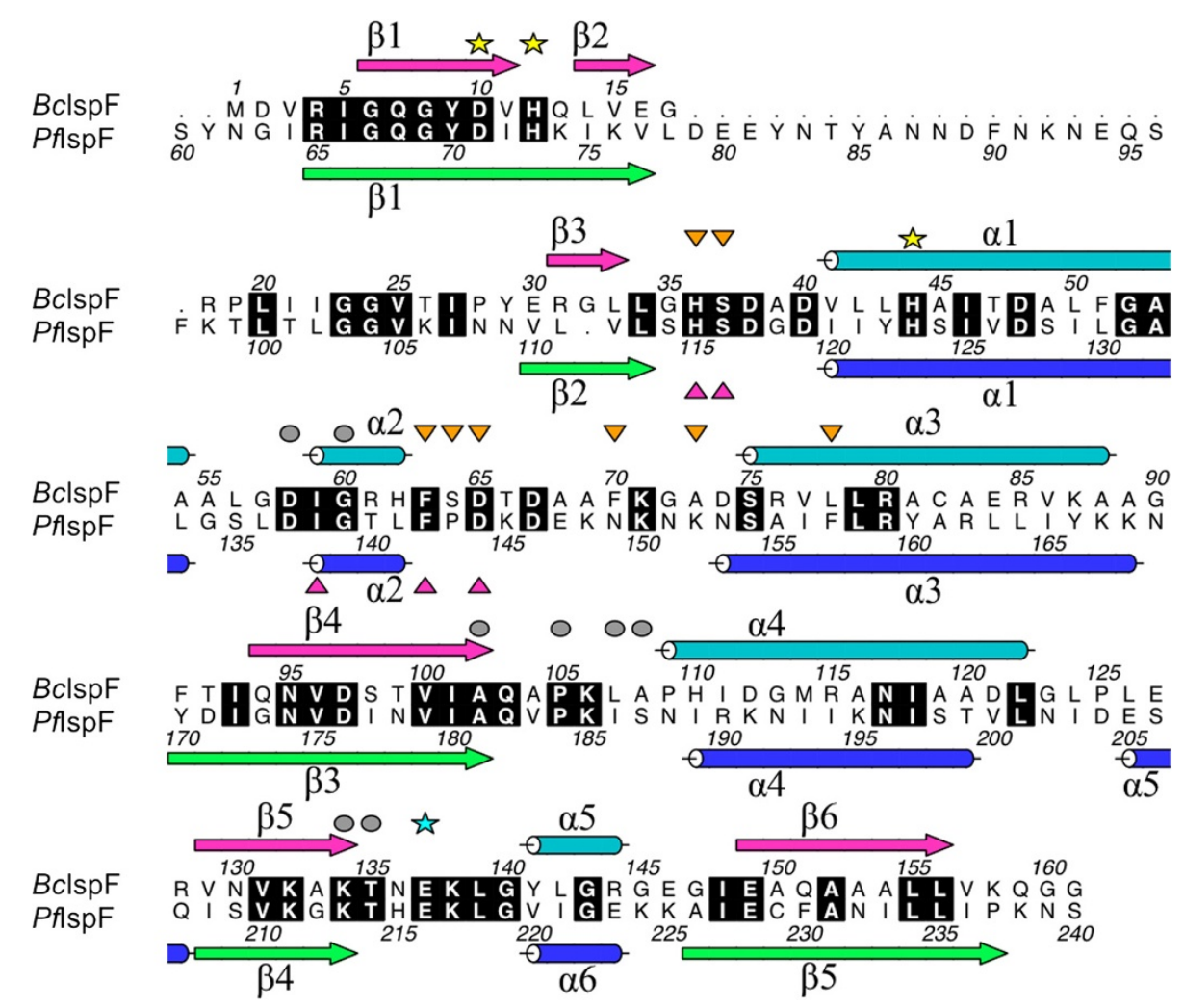

Figure 3 Structure-based sequence alignment of BclspF and PflspF. The alignment has been annotated with elements of secondary structure. Strictly conserved residues are highlighted in black. Three residues that coordinate $\mathrm{Zn}^{2+}$ are marked with a yellow star. Residues that bind CDP or CMP 1, are marked with a grey disk and those that bind CMP 2 with an orange triangle. Residues that bind MECPP in ECIspF [20] are marked with a magenta triangle. A conserved glutamate that binds either $\mathrm{Mg}^{2+}$ or $\mathrm{Mn}^{2+}$ in EclspF structures is highlighted with a cyan star. This figure was prepared using ALINE [29].

floor of the cavity. Anions such as sulfate, phosphate or pyrophosphate bind at the entrance to this cavity in several IspF structures, for example phosphate is present in $A t \mathrm{IspF}$ [30]. In the structure of BcIspF crystallized with $\left(\mathrm{NH}_{4}\right)_{2} \mathrm{SO}_{4}$ as a precipitant, a sulfate is bound by the side chain of Arg144. In $P f \mathrm{IspF}$, a sulfate binds close to this site but dislodged such that anion coordination involves the main chain amides of nearby residues, Val220 from all three subunits, rather than a basic side chain. When $B c$ IspF is crystallized in the presence of $\mathrm{Na}_{2} \mathrm{HPO}_{4}$, Tyr141 amide groups bind a phosphate in a similar fashion. Isoprenoid-species such as geranyl- or farnesylpyrophosphate have been observed in the central cavity of some IspF trimers and a possible role in feedback regulation has been suggested [31-33]. A molecule of di (hydroxyethyl)ether; a likely decomposition product or impurity of PEG 3350 used in crystallization, occupies the cavity in the BcIspF:2CMP structure (Table 2), possibly mimicking a prenyl chain. A solvated $\mathrm{Mg}^{2+}$ with octahedral coordination is present in the cavity of the $B c I s p F: C M P$ structure forming interactions similar to those observed in the structure of IspF from B. pseudomallei [27], data not shown.

\section{Complexes with CMP and CDP}

Residues from both subunits interact with and position cytidine nucleotides in the active site. These compounds constitute fragments of the substrate and provide clues about aspects of molecular recognition. The structurebased sequence alignment (Figure 3) and overlay of the active sites of BcIspF:CMP and Pf IspF:CDP complexes (Figure 4) indicate that the key enzyme-ligand interactions and aspects of the structure that are implicated in substrate specificity and the mechanism are highly conserved. Note that in the $P f I$ IspF:CDP complex two conformers of CDP are present that differ in the orientation of the $\beta$-phosphate group. These refined satisfactorily at occupancy levels of 0.6 and 0.4 .

In BcIspF, carbonyl groups from Ala102 and cisPro105 accept hydrogen bonds donated by cytosine N4, and the amide groups of Leu107 and Ala108 donate hydrogen bonds to cytosine $\mathrm{N} 3$ and $\mathrm{O} 2$ respectively. The ribose O2' forms a hydrogen bond with Asp58 from the adjacent subunit while the amide of Gly60, also from the adjacent subunit, hydrogen bonds to the ribose O3'. Thr135 amide and side chain hydroxyl groups form hydrogen bonds to the $\alpha$-phosphate. Lys134 NZ 


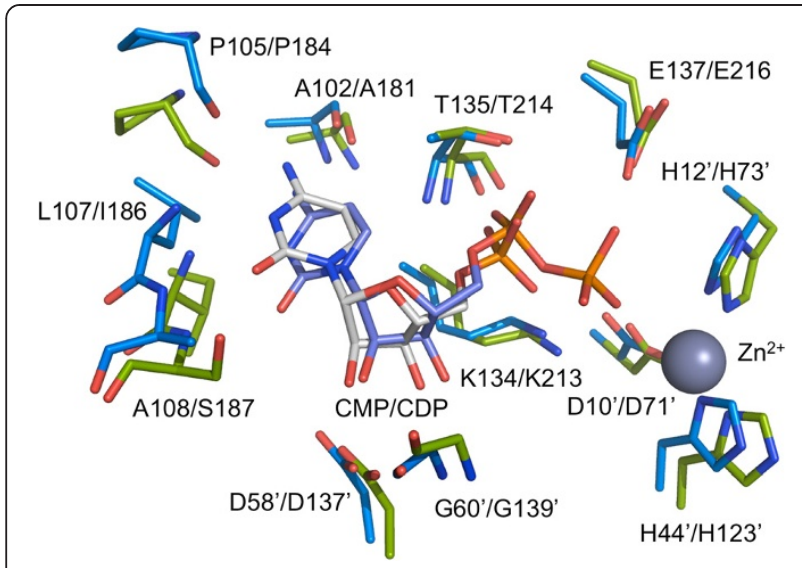

Figure 4 Superposition of the active site in BclspF and Pf IspF. Residues that bind CMP or CDP are displayed as sticks. Sequence numbers for BclspF are followed by those for PflspF, and residues contributed from the adjacent subunit are marked with'. BclspF and PflspF are colored cyan and green respectively. Key interactions are detailed in the text.

interacts with the CMP $\alpha$-phosphate, and may contribute to catalysis by helping to position the transition-state intermediate or, in conjunction with $\mathrm{Zn}^{2+}$, to align the substrate for nucleophilic attack. This interaction in $B c I s p F$ is reminiscent of that previously reported for the active site Lys132 in Thermus thermophilus IspF [34], except that in that case the lysine interacts with the $\beta$-phosphate. The side chain of Lys106 is positioned over the cytosine and contributes van der Waals contacts to stabilize the ligand pose. For clarity this residue is omitted in Figure 4.

We analysed the levels of conservation of these eight IspF residues detailed as interacting with CMP or CDP. The residues for which the side chain is key, the glycine and cis-proline are highly conserved in IspF, at greater than $95 \%$. Where main chain functional groups are used the nature of the side chain is less important and the level of conservation drops to $37 \%$ for the equivalent of Leu107 to $62 \%$ for Ala102 in BcIspF. Lys134 is anomalous. This is only lysine in $20 \%$ of the sequences and is more often a threonine, $76 \%$ of sequences. Presumably the reduction in size allows space that a water molecule could occupy to help facilitate substrate binding.

Surprisingly, a second molecule of CMP was observed in the active site when $B c I s p F$ was co-crystallized in the presence of $10 \mathrm{mM}$ ligand. This second CMP is likely due to the high concentration used and represents an artifact of crystallization, unlikely to have physiological significance. This new cytidine-binding site is referred to as position 2 and residues that bind this ligand are from the same subunit that binds the active site $\mathrm{Zn}^{2+}$, indeed the CMP 2 phosphate coordinates the metal ion (Figure 5). The binding of CMP 2 within the three active sites of the asymmetric unit is very similar, for example the main chain conformation of the $\alpha 2-\alpha 3$ loop and the positions of Leu78 and His36 interacting with van der Waals forces on either side of the pyrimidine and helping to position it is essentially the same. In addition the position of Phe63 that helps to position Leu78 is also conserved. Phe63 is strictly conserved in $96 \%$ of IspF sequences, Leu78 in $77 \%$. However, there are differences in the orientation of two side chains that change the detail of the hydrogen bonding interactions with CMP 2 . In active site A (Figure 6) two solvent mediated links are noted involving the carbonyl groups of Ser64, Phe70 and Ala73 and cytosine $\mathrm{O} 2$ and N3. A direct hydrogen bond is formed between N4 and the Ala73 carbonyl. The Phe70 and Ala73 carbonyl groups position a water molecule that binds cytosine N3 and the Ala73 carbonyl also interacts directly with cytosine N4. The carboxylate of Asp65 binds to the ribose O2'. In the other active sites (not shown), different rotamers of Ser37 place the side chain OG to accept a hydrogen bond from N4 but for Asp65 the rotamer orientations results in functional groups too distant for an interaction with the ribose. Overlay with the EcIspF-product complex shows that CMP 2 binds in the same location as MEcPP [20] and indeed exploits interactions with the same residues, the majority of which are conserved (Figures 3 and 7). Specifically, in common with observations regarding recognition of the pyrimidine moiety of substrates we note that residues that use side chain functional groups to interact with ligands in the MEcPP binding site are well conserved, those that use main chain groups less so. Ser37 is strictly conserved and Asp65 occurs in about $70 \%$ of IspF sequences but Ser64, Phe70 and Ala73 are strictly conserved in $4 \%, 43 \%$ and $58 \%$ respectively. The latter two residues are not conserved in $P f \mathrm{IspF}$, being replaced by asparagine and lysine respectively (Figure 3).

The binding pose of CMP 2 offers clues about molecular features that might be considered for ligand design targeting this area of the active site. Potential ligands could, for example, aim to extend out to recreate the hydrogen bonding interactions displayed by the two ordered water molecules shown in Figure 6. It might also be useful to test placement of a basic component to interact with the acidic Asp65.

\section{BclspF-citrate complex}

Attempts to produce unliganded $B c I$ spF crystals for ligand or fragment soaking experiments initially appeared to be successful and highly ordered samples were obtained. However, citrate was present in the best crystallization conditions and the electron density maps were consistent with this molecule coordinating the metal ion and therefore complicating ligand-binding studies. Two binding modes were observed. Citrate was well defined in one 


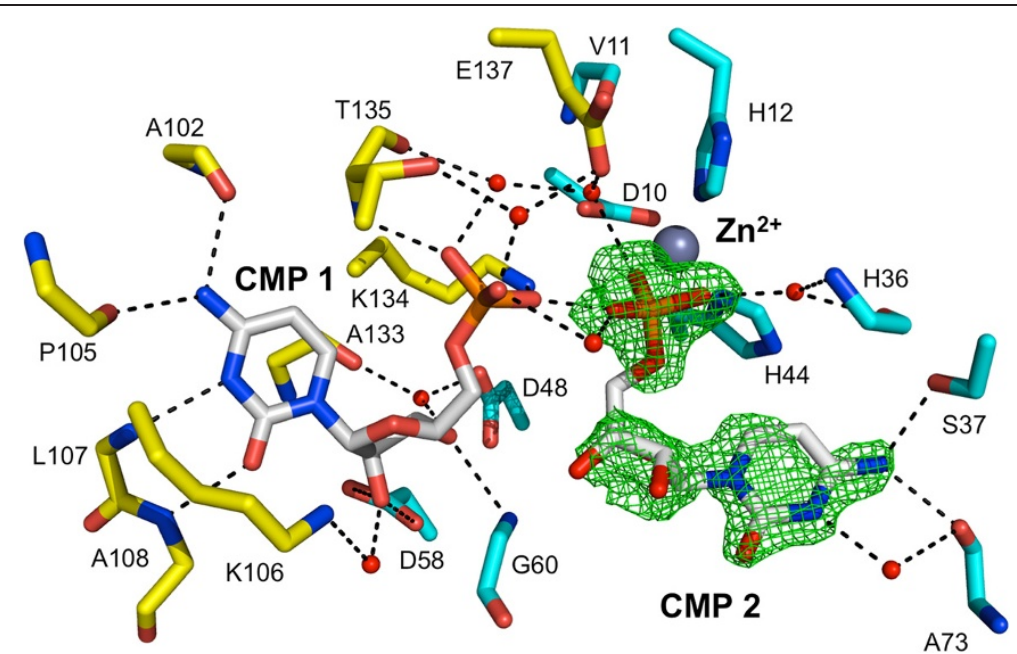

Figure 5 Binding pose of two cytidine nucleotides in BclspF. Hydrogen bonding interactions between BclspF, water molecules and both CMP molecules in one active site are depicted with black dashed lines. Residues that contribute to binding interactions only via the main chain are depicted without side chain atoms. Solvent molecules are depicted as red spheres. Components of one subunit are shown with $\mathrm{C}$ atoms yellow and for the other subunit, cyan. Electron density is displayed for CMP 2 as green chicken-wire corresponding to an $\left|F_{0}-F_{c}\right|$ map (omit map) contoured at $2.5 \sigma$.

active site with an average $B$-factor of about $23 \AA^{2}$, but less so in the other two where it was modeled with occupancy 0.75 and the average $B$-factors are approximately 37 and $43 \AA^{2}$. For comparison, the average $B$-factor for protein atoms in this structure is approximately $19 \AA^{2}$. The best-defined citrate (Figure 8 ) binds to the active site $\mathrm{Zn}^{2+}$ via both carboxylate and hydroxyl groups and this is also observed at one other site. Here the citrate forms hydrogen-bonding interactions with the main chain amides of His36 and Ser37, and side chains of Asp65 and Lys134. The interaction involving Asp65 is likely a consequence of the low $\mathrm{pH}$ at which crystals were obtained. Additional solvent mediated interactions to link citrate to the protein also occur (not shown). The normally flexible and poorly ordered $\alpha 2-\alpha 3$ loop appears to lock down over the bound citrate adopting a configuration similar to that observed in the EcIspF-MEcPP complex [20]. In the other

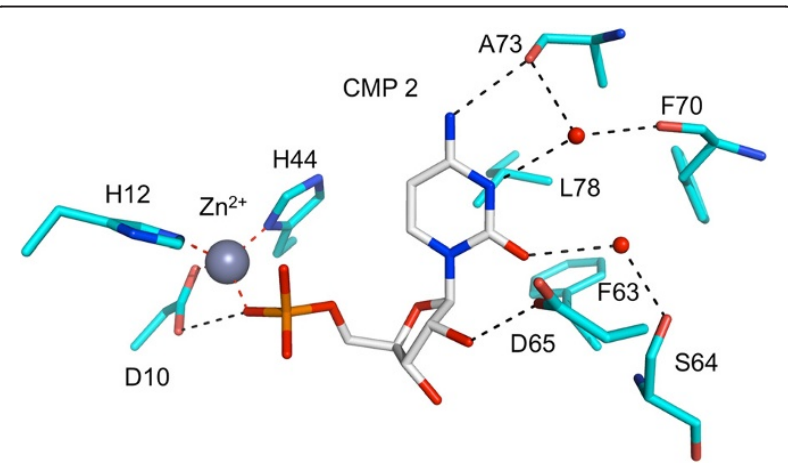

Figure 6 Key residues and interactions to bind CMP 2 in BclspF. The color scheme is the same as used in Figure 5. citrate-binding pose (not shown) only a carboxylate coordinates to $\mathrm{Zn}^{2+}$ but hydrogen bonds are also formed exploiting the same functional groups on the protein, the amides of His36 and Ser37, Ser37 OG, and Lys134 NZ. It is clear from these results, that any attempts to investigate ligand binding at the $\mathrm{Zn}^{2+}$ site will require crystallization conditions that do not include citrate.

Co-crystallization with potential $\mathrm{Zn}^{2+}$ coordinating ligands A screen of $\mathrm{Zn}^{2+}$-binding ligands previously identified L-tryptophan hydroxamate as a ligand for IspF suggesting that the presence of such a group may anchor ligands in the active site [25]. Subsequent studies with $B p I s p F$ reported a number of metal ion coordinating ligands [27]. Crystallization trials of $P f \mathrm{IspF}$ and $B c I s p F$ in the presence of several such $\mathrm{Zn}^{2+}$ coordinating ligands (e.g. fosmidomycin, benzohydroxamic acid, acetohydroxamic acid and pyrithione), testing a range of concentrations together with the absence or presence of CMP were carried out. Citrate was not present in these crystallization trials. Numerous datasets have been measured and analyzed but we have not observed any evidence of selected ligands at the $\mathrm{Zn}^{2+}$ site. In one case a $2.0 \AA$ resolution dataset was obtained from $B c I s p F$ co-crystallized with $10 \mathrm{mM}$ pyrithione. It quickly became evident that neither $\mathrm{Zn}^{2+}$ nor pyrithione were present in the structure (not shown) and this suggests that the ligand may have extracted $\mathrm{Zn}^{2+}$ from the active site.

\section{Conclusions}

The structures of IspF from a bacterial (BcIspF) and a protozoan $(P f \mathrm{IspF})$ pathogen have been determined and compared to orthologues. A high degree of structural 


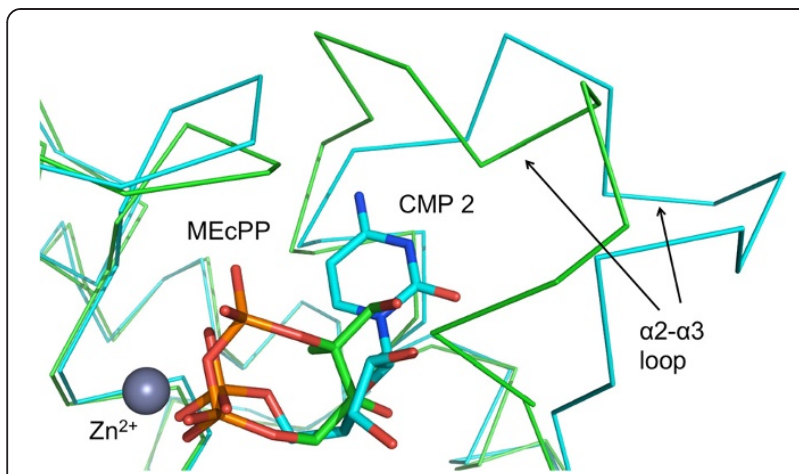

Figure 7 CMP 2 occupies the same site as MEcPP. An overlay of the EclspF product complex and BclspF:CMP 2. CMP 2 binds in a similar site as MEcPP and also coordinates $\mathrm{Zn}^{2+}$. The a2-a3 loop at one side of the binding site (EClspF: Phe61-Ser73; BclspF: Phe63-Ser75) adopts a different conformation

similarity in and around the active sites is noted. These proteins have been assessed for suitability as platforms for structure-based drug discovery. The cytidine-binding pocket is relatively rigid in IspF, whereas the pocket that binds the methylerythritol-phosphate portion of the substrate is relatively flexible. Numerous attempts to obtain the structure of protein-ligand complexes failed suggesting that the crystallization conditions may need to be adjusted or alternatives found. We note that in each case high ionic strength was necessary to obtain well-ordered crystals. Successful co-crystallization with small molecule ligands has been reported for $E c I s p F$ and $B p$ IspF $[24,25,27]$ and given the high degree of structural similarity in the IspF active site it might be prudent to use those enzymes for early stage drug discovery studies. Previously [26], AtIspF was used as a surrogate for $P f$ IspF due to difficulties in working with the later. We also noted problems with the solubility of $P f I s p F$ and subsequently identified conditions to circumvent this issue. However, given the high level of conservation we

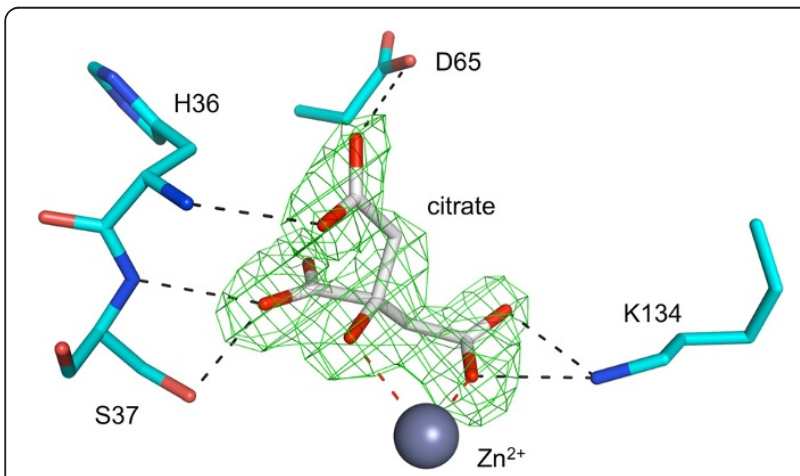

Figure $\mathbf{8}$ Citrate binding to $\mathbf{Z n}^{2+}$ in $\mathbf{B c l s p F}$. A well-resolved citrate binds to $\mathrm{Zn}^{2+}$. An omit map is displayed for citrate in green chicken wire contoured at $3 \sigma$. Residues are shown as sticks and a grey sphere represents $\mathrm{Zn}^{2+}$. Interactions are marked with dashed lines. Solvent mediated interactions are not shown. have described then any IspF might be considered a suitable surrogate for the apicomplexan enzymes. The unexpected observations that a second molecule of CMP can occupy the active site as well as the presence of citrate interacting with $\mathrm{Zn}^{2+}$ in $B c \mathrm{IspF}$ are noteworthy. These ligands provide templates for ligand design addressing metal ion coordination and interactions in the MEcPPbinding pocket.

\section{Methods}

\section{Protein production}

The gene encoding $B c I s p F$ was amplified from $B$. cenocepacia genomic DNA (strain J2315) by PCR using $5^{\prime}$ - CAT ATG GAC TTC AGA ATC GGA CAA GG $-3^{\prime}$ and 5' - GGA CCT CAG CCG CCC TGC TTC ACC -3' as the forward and reverse primers respectively (Thermo Scientific). The PCR product was ligated into TOPOBlunt-II (Invitrogen) then subcloned into a modified pET15b vector (Novagen), which produces a histidinetagged protein with a Tobacco Etch Virus (TEV) protease site. A single nucleotide error in the forward primer gave a single amino acid mutation F3V. The gene encoding IspF from $P$. falciparum strain 3D7, [GenBank: XP_001349603], was synthesized (Genscript) with codons optimized for recombinant expression in E. coli. The sequence encoding residues $1-59$, a predicted apicoplast targeting sequence, was excluded and the codon for Cys60 was replaced with one for serine. This synthetic gene was sub-cloned into the same modified $\mathrm{pET} 15 \mathrm{~b}$ vector as $B c$ ispF. Experimental procedures for recombinant protein production using $E$. coli BL-21 (DE3) Gold following published methods [19].

\section{Purification of $P f \mid s p F$}

$P f$ IspF precipitates at temperatures below $18^{\circ} \mathrm{C}$ therefore all procedures were performed at room temperature unless otherwise stated. Cells were harvested by centrifugation at $3000 \mathrm{~g}$ for 30 minutes at $18^{\circ} \mathrm{C}$ and re-suspended in $100 \mathrm{mM} \mathrm{KCl}, 100 \mathrm{mM} \mathrm{L}$-arginine, $50 \mathrm{mM}$ CHES, pH 9.5 (buffer A). DNaseI and a protease inhibitor tablet (EDTA-free, Roche) were added prior to cell lysis by passage through a French pressure cell at 16000 psi. Cell lysate was clarified by ultracentrifugation at $40000 \mathrm{~g}$ for 30 minutes at $18^{\circ} \mathrm{C}$ (Avanti centrifuge, Beckmann) and the supernatant was syringe filtered (Sartorius).

Lysate was loaded onto a nickel ion affinity chromatography column (5 mL HisTrap HP, GE Healthcare) using an FPLC system (Äkta Explorer, GE Healthcare). A linear concentration gradient of imidazole was applied with elution of $P f$ IspF occurring at $200 \mathrm{mM} \mathrm{mM}$ imidazole. The fractions containing IspF were pooled and dialyzed against buffer $\mathrm{A}$. The affinity tag (His-tag) was cleaved with His-tagged TEV protease at $20^{\circ} \mathrm{C}$ for 16 hours. Protease-treated sample was re-applied to a nickel 
ion affinity chromatography column, and the cleaved protein eluted. Fractions were analyzed by sodium dodecyl sulfate polyacrylamide gel electrophoresis (SDSPAGE) and those containing $P f$ IspF were pooled. The sample was further purified on a size-exclusion chromatography column (Superdex 200 26/60, GE Healthcare) equilibrated with buffer $\mathrm{A}$. This column had been calibrated with molecular weight standards (Bio-Rad). The level of $P f$ IspF purity was confirmed by SDS-PAGE and matrix-assisted laser desorption/ionization timeof-flight mass spectrometry. Protein concentration was estimated spectrophotometrically using a theoretical extinction coefficient, $\varepsilon$ : $11920 \mathrm{M}^{-1} \mathrm{~cm}^{-1}$ at $280 \mathrm{~nm}$, calculated using ProtParam [35].

\section{Purification of $B c l s p F$}

$B c$ IspF was purified in similar fashion to $P f$ IspF except that a different buffer, (100 mM NaCl, $100 \mathrm{mM}$ Tris$\mathrm{HCl}, \mathrm{pH} 7.5$, buffer B) was used. Removal of the His-tag reduced the solubility of the protein significantly. Once this problem was identified the tag was left in place. The temperature sensitivity observed for $P f$ IspF was not seen for $B c$ IspF and samples were kept either on ice or at $4^{\circ} \mathrm{C}$ throughout. $B c$ IspF concentration was measured using the Bradford assay (Thermo Scientific).

\section{Screening for crystallization conditions}

An automated liquid-handling system (Phoenix, Art Robbins) was used for screening crystallization conditions in combination with commercially available screens. All samples were filtered through a $0.1 \mu \mathrm{m}$ PVDF filter (Ultrafree, Millipore) immediately prior to screening. Sitting-drops were formed by mixing $100 \mathrm{~nL}$ sample with either 100 or $200 \mathrm{~nL}$ of reservoir. Reservoir volumes were $60 \mu \mathrm{l}$. Conditions identified from the screens were subsequently scaled up and optimized.

\section{Crystallization of a PfIspF:CDP complex and unliganded PfIspF}

Pf IspF was concentrated to $6 \mathrm{mg} \mathrm{mL}^{-1}$ using a $10 \mathrm{kDa}$ cutoff centrifugal filter (Vivaspin 20, Sartorius) to provide a stock solution for crystallization. The sample was supplemented with $\mathrm{MgCl}_{2}(2 \mathrm{mM})$ and CDP disodium salt (2 mM, Sigma-Aldrich). Hanging drops were prepared consisting of $2 \mu \mathrm{l}$ sample mixed with $2 \mu \mathrm{l}$ of reservoir (1.8-2.5 M $\left(\mathrm{NH}_{4}\right)_{2} \mathrm{SO}_{4}, 5 \mathrm{mM} \mathrm{ZnCl}_{2}$ and $100 \mathrm{mM}$ Bis-Tris, pH 5.5). Diffusion against $1000 \mu \mathrm{l}$ of reservoir led to the formation of small prismatic crystals (approximate dimensions $0.15 \times 0.15 \times 0.15 \mathrm{~mm}$ ) within $2-4$ days. Isomorphous crystals were also obtained with $10 \mathrm{mM}$ fosmidomycin present in the crystallization drop. Crystals were transferred to drops containing saturated sucrose solution, for $\sim 5$ seconds before flash cooling in liquid nitrogen.

\section{Crystallization of BclspF complexes}

$B c$ IspF was concentrated to $5 \mathrm{mg} \mathrm{mL}^{-1}$ in buffer $\mathrm{B}$, similar to $P f$ IspF and the solution adjusted to include $2 \mathrm{mM}$ $\mathrm{MgCl}_{2}$ and $20 \mathrm{mM} \mathrm{CMP} \mathrm{disodium} \mathrm{salt} \mathrm{(Sigma-Aldrich).}$ A second sample was prepared at $10 \mathrm{mg} \mathrm{mL}^{-1}$ in buffer $\mathrm{C}(100 \mathrm{mM} \mathrm{NaCl}, 2 \mathrm{mM} \mathrm{MgCl}, 100 \mathrm{mM}$ sodium formate, $\mathrm{pH} 5.0)$ to which CMP (2 mM) was also added.

The BcIspF CMP 2 structure was obtained from crystals grown by mixing $2 \mu \mathrm{L}$ of the sample in buffer B with reservoir $(2 \mu \mathrm{L})$ containing 25\% w/v PEG 3350, $2.2 \mathrm{M}$ $\left(\mathrm{NH}_{4}\right)_{2} \mathrm{SO}_{4}, 0.1 \mathrm{M}$ sodium formate, $\mathrm{pH} 5.0$, and $1 \% \mathrm{v} / \mathrm{v}$ dioxane. Orthorhombic blocks reached maximum size within ten days. A crystal of approximate dimensions $0.15 \times 0.10 \times 0.10 \mathrm{~mm}$ was used for data collection. Buffer B supplemented with $20 \% \mathrm{v} / \mathrm{v}$ glycerol was used as a cryoprotectant.

The second sample gave the $B c I s p F$ CMP structure. This was crystallized by mixing $2 \mu \mathrm{L}$ with $4 \mu \mathrm{L}$ reservoir containing 5\% w/v PEG 1000, 33\% v/v ethanol, $0.1 \mathrm{M}$ $\mathrm{Na}_{2} \mathrm{HPO}_{4}, \mathrm{pH} 4.0$, and $2 \% \mathrm{v} / \mathrm{v}$ dioxane. A crystal of approximate dimensions $0.25 \times 0.10 \times 0.10 \mathrm{~mm}$ grew over six days and was used for data collection. A mixture of buffer $C$ with reservoir (1:2), replacing PEG 1000 with PEG 4000 at $25 \% \mathrm{w} / \mathrm{v}$, was used as a cryoprotectant.

The $B c$ IspF:citrate structure was derived from protein concentrated to $10 \mathrm{mg} \mathrm{mL}^{-1}$ in buffer D $(100 \mathrm{mM} \mathrm{NaCl}$, $100 \mathrm{mM}$ sodium formate, $\mathrm{pH} 5.0$ ), and crystallized by mixing $(1.5 \mu \mathrm{L})$ with a reservoir $(3 \mu \mathrm{L})$ containing $5 \% \mathrm{w} /$ v PEG 1000, 36\% v/v ethanol, $0.1 \mathrm{M} \mathrm{Na}_{2} \mathrm{HPO}_{4}$ and $0.1 \mathrm{M}$ citric acid, $\mathrm{pH}$ 4.2. A different crystal form to that previously found, grew within 4 days to approximate dimensions $0.4 \times 0.1 \times 0.1 \mathrm{~mm}$. A mixture of sample buffer with reservoir (1:2), replacing PEG 1000 with PEG 4000 at $25 \%$ w/v, was used as a cryoprotectant. Datasets for the $B c$ IspF complex crystals were collected on the inhouse X-ray system as described for PfIspF.

Crystals were screened in-house using a rotating-anode X-ray source (MicroMax $007 \mathrm{HF}$, Rigaku) equipped with a dual image plate detector (RAXIS $\mathrm{IV}^{++}$). Diffraction data from the PfIspF:CDP complex were collected on beamline ID29 at the European Synchrotron Radiation Facility (ESRF, Grenoble) at $-170^{\circ} \mathrm{C}$ using an ADSC Quantum 315r CCD detector. Data from the crystals grown in the presence of fosmidomycin were collected in-house. Subsequently it was determined that fosmidomycin was not ordered and this is therefore considered to be an unliganded Pf IspF structure. Datasets for the BcIspF complex crystals were all collected on the in-house X-ray system described above.

\section{Data processing, structure solution and refinement}

Diffraction data were indexed and integrated using MOSFLM [36] or XDS [37] and scaled with SCALA [38] with $5 \%$ of data flagged for $R_{\text {free }}$ calculations. The $R_{\text {free }}$ 
flag was maintained for isomorphous structures. Initial structures were solved by molecular replacement using PHASER [39]. Different search models, edited to remove all non-protein atoms, were used for these calculations. The coordinates of $E$. coli IspF [PDB:1GX1] with 33\% sequence identity, [19] and B. pseudomallei [PDB:3F0G] 63\% identity, [27] were used to determine the $P f \mathrm{IspF}$ : $\mathrm{CDP}$ and $B c I s p F$ :2CMP structures respectively. $B$-factors of the replacement models were adjusted to match the Wilson $B$-factor derived from scaling of the data. Subsequently these parent structures were used as the starting points for analyses of the other structures. Crystals of $P f$ IspF display differing degrees of twinning as recognised in SCALA and a twin fraction of 0.14 was applied to the CDP complex.

Refinement calculations were performed with REFMAC5 [40] and the resulting models together with electron density and difference density maps were inspected in COOT, which also allowed for model adjustment to improve the fit to density [41]. Water molecules, ions, ligands and conformational rotamers were added to the models as the refinements progressed. In the case of citrate molecules binding to $B c I s p F$, one site was well ordered but the other two sites displayed more diffuse electron density and a decision was taken to set the occupancy to 0.75 . These then refined satisfactorily with no residual features in the resulting difference density maps. Strict NCS restraints were employed in the early stages of refinement and then removed towards the latter stages. To confirm the presence of ligand molecules in the final models, $\left|F_{\mathrm{o}}-\mathrm{F}_{\mathrm{c}}\right|$ electron density difference maps, referred to as 'omit maps', were prepared by excluding ligands from $\mathrm{F}_{\mathrm{c}}$ calculation, several cycles of refinment in REFMAC5 and inspection of the maps in COOT. The validation tools in COOT and the MolProbity server [42] were used to assess model geometry. Comparisons with structures in the PDB were performed using the DALI server [28]. The Protein Interfaces, Surfaces \& Assemblies server, [43] was used to calculate surface and interface areas and figures were prepared with PyMOL [44].

\section{Sequence analyses}

A search in UniProt for IspF sequences using the E.C. number [4.6.1.12] returned 2458 entries. The list was filtered down to 2229 by excluding the bifunctional IspDF examples and fragmentary protein sequences. Sequences with greater than or equal to $90 \%$ identity were clustered and a single representative sequence identified for each cluster, reducing the list to 876 sequences. These were inspected and a decision taken to remove a number of sequences that still appeared to be fragmentary. A final set of $854 \mathrm{IspF}$ sequences were submitted to the European Bioinformatics Institute-ClustalOmega multiple sequence alignment server [45]. The alignment was displayed in
Jalview [46] and percentage conservation scores were manually calculated for all residues marked in Figure 3.

\section{Abbreviations}

CDP: Cytidine 5'-diphosphate; CDP-MEP: 4-diphosphocytidyl-2C-methyl-Derythritol-2-phosphate; CMP: Cytidine 5'-monophosphate; IspF: 2C-methyl-Derythritol-2,4-cyclodiphosphate synthase; MEcPP: 2C-methyl-D-erythritol-2,4cyclodiphosphate; MEP: 2C-methyl-D-erythritol-4-phosphate;

MVA: Mevalonate; NCS: Non-crystallographic symmetry; RMSD: Root-meanstandard deviation; SDS-PAGE: Sodium dodecyl sulfate polyacrylamide gel electrophoresis.

\section{Competing interests}

The authors declare they have no competing interests.

\section{Authors' contributions}

Conceived and designed the experiments: PEFO'R JK-T AD WNH. Performed the experiments: PEFO'R JK-T PKF AD. Analysed the data: PEFO'R JK-T PKF WNH. Wrote the paper: PEFO'R JK-T WNH. All authors read and approved the final manuscript.

\section{Acknowledgments}

We thank Scott Cameron for assistance and staff at the ESRF for access to facilities and excellent support. Coordinates and structure factors are deposited in the PDB under accession codes: 4C81, 4C82, 4C8E, 4C8G, and 4C8I. Funded by the Wellcome Trust [grants 082596, 094090, 100476], the European Commission [the Aeropath project], and a Biotechnology and Biological Sciences Research Council - Pfizer studentship.

\section{Author details}

${ }^{1}$ Division of Biological Chemistry and Drug Discovery, College of Life Sciences, University of Dundee, Dundee, DD1 5EH, UK. ${ }^{2}$ Current address, Department of Crystal Chemistry and Crystal Physics, Faculty of Chemistry, Jagiellonian University, 30-060 Kraków, Poland.

Received: 23 October 2013 Accepted: 20 December 2013 Published: 10 January 2014

\section{References}

1. Hunter WN: The non-mevalonate pathway of isoprenoid precursor biosynthesis. J Biol Chem 2007, 282:21573-21577.

2. Zhao L, Chang WC, Xiao Y, Liu HW, Liu P: Methylerythritol phosphate pathway of isoprenoid biosynthesis. Annu Rev Biochem 2013, 82:497-530.

3. Rohmer M, Knani M, Simonin P, Sutter B, Sahm H: Isoprenoid biosynthesis in bacteria: a novel pathway for the early steps leading to isopentenyl diphosphate. Biochem J 1993, 295:517-524.

4. Rohdich F, Kis K, Bacher A, Eisenreich W: The non-mevalonate pathway of isoprenoids: genes, enzymes and intermediates. Curr Opin Chem BiOl 2001, 5:535-540

5. Hunter WN: Isoprenoid precursor biosynthesis offers potential targets for drug discovery against diseases caused by apicomplexan parasites. Curr Top Med Chem 2011, 11:2048-2059.

6. Rohdich F, Bacher A, Eisenreich W: Isoprenoid biosynthetic pathways as anti-infective drug targets. Biochem Soc Trans 2005, 33:785-791.

7. Lichtenthaler HK: The 1-deoxy-D-xylulose-5-phosphate pathway of isoprenoid biosynthesis in plants. Annu Rev Plant Physiol Plant Mol Biol 1999, 50:47-65

8. van Dooren $\mathrm{GG}$, Striepen B: The algal past and parasite present of the apicoplast. Annu Rev Microbiol 2013, 67:271-289.

9. Yeh E, DeRisi JL: Chemical rescue of malaria parasites lacking an apicoplast defines organelle function in blood-stage Plasmodium falciparum. PLOS Biol 2011, 9:1-10.

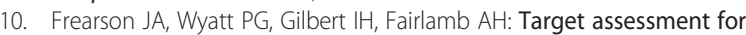
antiparasitic drug discovery. Trends Parasitol 2007, 23:589-595.

11. Buetow $L$, Brown AC, Parish T, Hunter WN: The structure of Mycobacteria 2C-methyl-D-erythritol-2,4-cyclodiphosphate synthase, an essential enzyme, provides a platform for drug discovery. BMC Struct Biol 2007, 7:68.

12. Campbell TL, Brown ED: Characterization of the depletion of 2-C-methylD-erythritol-2,4-cyclodiphosphate synthase in Escherichia coli and Bacillus subtilis. J Bacterio/ 2002, 184:5609-5618. 
13. Campos N, Rodríguez-Concepción M, Sauret-Güeto S, Gallego F, Lois L, Boronat A: Escherichia coli engineered to synthesize isopentenyl diphosphate and dimethylallyl diphosphate from mevalonate: a novel system for the genetic analysis of the 2-C-methyl-D-erythritol 4-phosphate pathway for isoprenoid biosynthesis. Biochem J 2001, 353:59-67.

14. Freiberg $\mathrm{C}$, Wieland B, Spaltmann F, Ehlert $\mathrm{K}$, Brotz $\mathrm{H}$, Labischinski $\mathrm{H}$ : Identification of novel essential Escherichia coli genes conserved among pathogenic bacteria. J Mol Microbiol Biotechnol 2001، 3:483-489.

15. Sauret-Güeto S, Ramos-Valdivia A, Ibáñez E, Boronat A, Rodríguez-Concepción M: Identification of lethal mutations in Escherichia coli genes encoding enzymes of the methylerythritol phosphate pathway. Biochem Biophys Res Commun 2003, 307:408-415.

16. Shigi $Y$ : Inhibition of bacterial isoprenoid synthesis by fosmidomycin, a phosphonic acid-containing antibiotic. J Antimicrob Chemother 1989, 24:131-145.

17. Okuhara M, Kuroda Y, Goto T, Okamoto M, Terano H, Kohsaka M, Aoki H, Imanaka H: Studies on new phosphonic acid antibiotics I. FR-900098, isolation and characterization. J Antibiot 1980, 33:13-17.

18. Jomaa H, Wiesner J, Sanderbrand S, Altincicek B, Wiedemeyer C, Hintz M, Türbachova I, Eberl M, Zeidler J, Lichtenthaler HK, Soldati D, Beck E: Inhibitors of the nonmevalonate pathway of isoprenoid biosynthesis as antimalarial drugs. Science 1999, 285:1573-1576.

19. Kemp LE, Bond CS, Hunter WN: Structure of 2C-methyl-D-erythritol 2,4-cyclodiphosphate synthase: an essential enzyme for isoprenoid biosynthesis and target for antimicrobial drug development. Proc Natl Acad Sci 2002, 99:6591-6596.

20. Steinbacher S, Kaiser J, Wungsintaweekul J, Hecht S, Eisenreich W, Gerhardt S, Bacher A, Rohdich F: Structure of 2C-methyl-D-erythritol-2,4-cyclodiphosphate synthase involved in mevalonate-independent biosynthesis of isoprenoids. J Mol Biol 2002, 316:79-88.

21. Gabrielsen M, Bond CS, Hallyburton I, Hecht S, Bacher A, Eisenreich W, Rohdich F, Hunter WN: Hexameric assembly of the bifunctional methylerythritol 2,4-cyclodiphosphate synthase and protein-protein associations in the deoxy-xylulose-dependent pathway of isoprenoid precursor biosynthesis. J Biol Chem 2004, 279:52753-52761.

22. Gabrielsen M, Rohdich F, Eisenreich W, Gräwert T, Hecht S, Bacher A, Hunter WN: Biosynthesis of isoprenoids: a bifunctional IspDF enzyme from Campylobacter jejuni. Eur J Biochem 2004, 271:3028-3035.

23. Baumgartner C, Eberle C, Diederich F, Lauw S, Rohdich F, Eisenreich W, Bacher A: Structure-based design and synthesis of the first weak non-phosphate inhibitors for IspF, an enzyme in the non-mevalonate pathway of isoprenoid biosynthesis. Helv Chim Acta 2007, 90:1043-1068.

24. Crane CM, Kaiser J, Ramsden NL, Lauw S, Rohdich F, Eisenreich W, Hunter WN, Bacher A, Diederich F: Fluorescent inhibitors for IspF, an enzyme in the non-mevalonate pathway for isoprenoid biosynthesis and a potential target antimalarial therapy. Angew Chem Int Ed 2006, 45:1069-1074.

25. Ramsden NL, Buetow L, Dawson A, Kemp LA, Ulaganathan V, Brenk R, Klebe G, Hunter WN: A structure-based approach to ligand discovery for 2C-methyl-D-erythritol-2,4-cyclodiphosphate synthase: A target for antimicrobial therapy. J Med Chem 2009, 52:2531-2542.

26. Geist JG, Lauw S, Illarionova V, Illarionov B, Fischer M, Gräwert T, Rohdich F, Eisenreich W, Kaiser J, Groll M, Scheurer C, Wittlin S, Alonso-Gómez JL, Schweizer WB, Bacher A, Diederich F: Thiazolopyrimidine inhibitors of 2-methylerythritol 2,4-cyclodiphosphate synthase (IspF) from Mycobacterium tuberculosis and Plasmodium falciparum. ChemMedChem 2010, 5:1092-1101.

27. Begley DW, Hartley RC, Davies DR, Edwards TE, Leonard JT, Abendroth J, Burris CA, Bhandari J, Myler PJ, Staker BL, Stewart LJ: Leveraging structure determination with fragment screening for infectious disease drug targets: MECP synthase from Burkholderia pseudomallei. J Struct Funct Genomics 2011, 12:63-76.

28. Holm L, Rosenström P: Dali server: conservation mapping in 3D. Nucleic Acids Res 2010, 38:W545-W549.

29. Bond CS, Schüttelkopf AW: ALINE: a WYSIWYG protein-sequence alignment editor for publication-quality alignments. Acta Cryst D 2009, 65:510-512.

30. Calisto BM, Perez-Gil J, Bergua M, Querol-Audi J, Fita I, Imperial S: Biosynthesis of isoprenoids in plants: structure of the 2 C-methyl-D-erithrytol 2, 4-cyclodiphosphate synthase from Arabidopsis thaliana. Comparison with the bacterial enzymes. Protein Sci 2007, 16:2082-2088.

31. Kemp LE, Alphey MS, Bond CS, Ferguson MA, Hecht S, Bacher A, Eisenreich $W$, Rohdich F, Hunter WN: The identification of isoprenoids that bind in the intersubunit cavity of Escherichia coli 2C-methyl-D-erythritol-2, 4-cyclodiphosphate synthase by complementary biophysical methods. Acta Cryst D 2005, 61:45-52.

32. Ni S, Robinson H, Marsing GC, Bussiere DE, Kennedy MA: Structure of 2C-methyl-D-erythritol-2,4-cyclodiphosphate synthase from Shewanella oneidensis at $1.6 \AA \AA$ : identification of farnesyl pyrophosphate trapped in a hydrophobic cavity. Acta Cryst D 2004, 60:1949-1957.

33. Sgraja T, Kemp LE, Ramsden N, Hunter WN: A double mutation of Escherichia coli 2C-methyl-D-erythritol-2,4-cyclodiphosphate synthase disrupts six hydrogen bonds with, yet fails to prevent binding of, an isoprenoid diphosphate. Acta Cryst F 2005, 61:625-629.

34. Kishida H, Wada T, Unzai S, Kuzuyama T, Takagi M, Terada T, Shirouzu M, Yokoyama S, Tame JRH, Park S: Structure and catalytic mechanism of 2-C-methyl-D-erythritol 2,4-cyclodiphosphate (MECDP) synthase, an enzyme in the non-mevalonate pathway of isoprenoid synthesis. Acta Cryst D 2003, 59:23-31.

35. Gasteiger E, Hoogland C, Gattiker A, Duvand S, Wilkins MR, Appel RD, Bairoch A: Protein identification and analysis tools on the ExPASy server. Totowa, NJ, USA: Humana Press, The Proteomics Protocols Handbook; 2005:571-607

36. Battye TGG, Kontogiannis L, Johnson O, Powell HR, Leslie AGW: iMOSFLM: a new graphical interface for diffraction-image processing with MOSFLM. Acta Cryst D 2011, 67:271-281.

37. Kabsch W: XDS. Acta Cryst D. 2010, 66:125-132

38. Evans P: Scaling and assessment of data quality. Acta Cryst D 2006, 62:72-82.

39. McCoy AJ, Grosse-Kunstleve RW, Adams PD, Winn MD, Storoni LC, Read RJ: Phaser crystallographic software. J Appl Cryst 2007, 40:658-674.

40. Murshudov GN, Skubák P, Lebedev AA, Pannu NS, Steiner RA, Nicholls RA, Winn MD, Long F, Vagin AA: REFMAC5 for the refinement of macromolecular crystal structures. Acta Cryst D 2011, 67:355-367.

41. Emsley P, Lohkamp B, Scott WG, Cowtan K: Features and development of Coot. Acta Cryst D 2010, 66:486-501.

42. Chen VB, Arendall WB, Headd JJ, Keedy DA, Immormino RM, Kapral GJ, Murray LW, Richardson JS, Richardson DC: MolProbity: all-atom structure validation for macromolecular crystallography. Acta Cryst D 2010, 66:12-21.

43. Krissinel $E$, Henrick $K$ : Inference of macromolecular assemblies from crystalline state. J Mol Biol 2007, 372:774-797.

44. De Lano WL: The PyMOL Molecular Graphics System. : Schrödinger, LLC; 2002.

45. Sievers F, Wilm A, Dineen DG, Gibson TJ, Karplus K, Li W, Lopez R, McWilliam H, Remmert M, Söding J, Thompson JD, Higgins D: Fast, scalable generation of high-quality protein multiple sequence alignments using Clustal Omega. Mol Syst Biol 2011, 7:539.

46. Waterhouse AM, Procter JB, Martin DM, Clamp M, Barton GJ: Jalview Version 2-a multiple sequence alignment editor and analysis workbench. Bioinformatics 2009, 25:1189-1191.

\section{doi:10.1186/1472-6807-14-1}

Cite this article as: O'Rourke et al:: Crystal structures of IspF from Plasmodium falciparum and Burkholderia cenocepacia: comparisons inform antimicrobial drug target assessment. BMC Structural Biology 2014 14:1

\section{Submit your next manuscript to BioMed Central and take full advantage of:}

- Convenient online submission

- Thorough peer review

- No space constraints or color figure charges

- Immediate publication on acceptance

- Inclusion in PubMed, CAS, Scopus and Google Scholar

- Research which is freely available for redistribution 